\title{
A NEW CO THIRD-ORDER SHEAR DEFORMATION THEORY FOR THE NONLINEAR FREE VIBRATION ANALYSIS OF STIFFENED FUNCTIONALLY GRADED PLATES
}

\author{
Hoang Lan Ton-That \\ Department of Civil Engineering, HCMC University of Architecture, Vietnam

\begin{abstract}
Nonlinear free vibration of stiffened functionally graded plates is presented by using the finite element method based on the new CO third-order shear deformation theory. The material properties are assumed to be graded in the thickness direction by a power-law distribution. Based on the Von Karman theory and the third-order shear deformation theory, the nonlinear governing equations of motion are derived from the Hamilton's principle. An iterative procedure based on the Newton-Raphson method is employed in computing the natural frequencies and mode shape. The comparison between these solutions and the other available ones suggests that this procedure is characterized by accuracy and efficiency.
\end{abstract}

Key Words: Nonlinear Free Vibration, Functionally Graded Material, Stiffened Plate, Third-order Shear Deformation Theory

\section{INTRODUCTION}

The plates with stiffeners are often used in several fields of engineering such as medical, weapon, nuclear reactor construction, aerospace, etc. to improve stiffness of the structures. Many different ways are applied to analyzing plate structures in general as well as stiffened plate structures in particular; they are listed as Rayleigh-Ritz method [1], finite difference method [2, 3], finite element method (FEM) [4-15], constraint method $[16,17]$, mesh-free method [18-20], semi analytical finite defference method [21, 22], finite strip method [23-25], boundary element method [26, 27], integral transform approach [28], etc. The most important issue of this type of structure is the connection between the plate and the stiffeners. For example, Peng et al [19] used the first order shear deformation theory as well as the element-free Galerkin method to study the compatibility conditions between the plate and the stiffeners when they work together, etc. Evidently numerical methods are essential for calculating stiffened structures, in which the FEM is the most popular because of

Received June 29, 2020 / Accepted October 03, 2020

Corresponding author: Hoang Lan Ton-That

Department of Civil Engineering, HCMC University of Architecture, 196 Pasteur, District 3, HCMC, Vietnam.

E-mail: lan.tonthathoang@uah.edu.vn 
its efficiency and stability. Chattopadhyay et al. as well as Holopainen [29, 30] analyzed nonlinear static of composite stiffened plates based on the first order shear deformation theory and the FEM method or used a new finite model for a linear free vibration analysis of stiffened plates, which is based on the nine-node quadrilateral element related to mixed interpolation of tensorial components. Functionally graded materials with two constituents e.g. ceramic and metal from ceramic surface to metal surface are widely applied. In recent years, many surveys have been carried out in the area of functionally graded plates. The thermoelastic deformations and vibration behaviors with exact solutions were given by Vel and Batra [31]. Stress-driven nonlocal elasticity for nonlinear vibration characteristics of carbon/boron-nitride hetero-nanotube subject to magneto-thermal environment was firstly introduced by Sedighi and Malikan in [32]. The nonlinear vibration and static deflection problems of actuated hybrid nanotubes based on the stress-driven nonlocal integral elasticity was studied in [33] by Ouakad et al. On the other hand, Qian et al. [34] also analyzed this kind of structures based on the meshless local Petrov-Galerkin (MLPG) method. Thau and Choi showed the bending and free vibration behaviors of functionally graded plates based on the first-order shear deformation theory. Furthermore, concerning the MLPG method, the highorder shear and normal deformation plate theory was used to analyze thick functionally graded plates by Gilhooly et al. Some papers of Liew reviewed the meshless methods for composite plate/shell structures. A review of Jha involved the listing of studies for this structure. Further, Reddy proposed a general formulation related to the third-order shear deformation plate theory and the finite element model. An isogeometric analysis and a collocation method employing the shear deformation theory were also applied to the analysis of functionally graded plates by Valizadeh et al. or Ferreira et al., Zhang and Zhou, Prakash as well as Singha who also proposed a formulation to study linear and nonlinear behaviors of the functionally graded plates with respect to the physical neutral surface. An efficient three-node finite shell element for linear and nonlinear analyses of composite structures was also given by Marinkovíc et al. [14, 35]. Shi's third-order shear deformation theory with its necessary stability was first used for a functionally graded plate structure analysis in thermal environment by Bui et al. [7]. Besides, the C0 type of this theory was also used in the analysis of functionally graded skew plates by Ton [12]. And now, the C0 type of Shi's theory is applied to analyzing stiffened functionally graded plate structures. With the third-order shear deformation theory, we recognize that it is widely used because it does not need shear correction factors while it gives accurate transverse shear stresses. But with low-order finite elements such as four-node quadrilateral element, the need of C1 continuous approximation for the displacement fields in the third-order shear deformation theory causes some impediments. To overcome these shortcomings, the third-order shear deformation theory is a revised form which only requires $\mathrm{C} 0$ continuity for displacement fields. In the $\mathrm{C} 0$ third-order shear deformation theory, two additional variables are joined, and thence the first derivative of transverse displacements is only required, respectively.

The body of this paper is organized into four Sections. In Sect.2, finite element formulation based on the $\mathrm{C} 0$ new third-order shear deformation theory for stiffened functionally graded plates is presented. Several examples are subsequently presented in Sect.3. The paper ends with some concluding remarks in the last Section. 


\section{FINITE ELEMENT FORMULATION}

Let us consider a stiffened functionally graded plate with geometry as plotted in Fig. 1a. The bottom and top faces of plate are to be fully metallic and ceramic, respectively. The mid-plane of the plate is $x y$-plane, while the $z$-axis is perpendicular to the $x y$-plane.

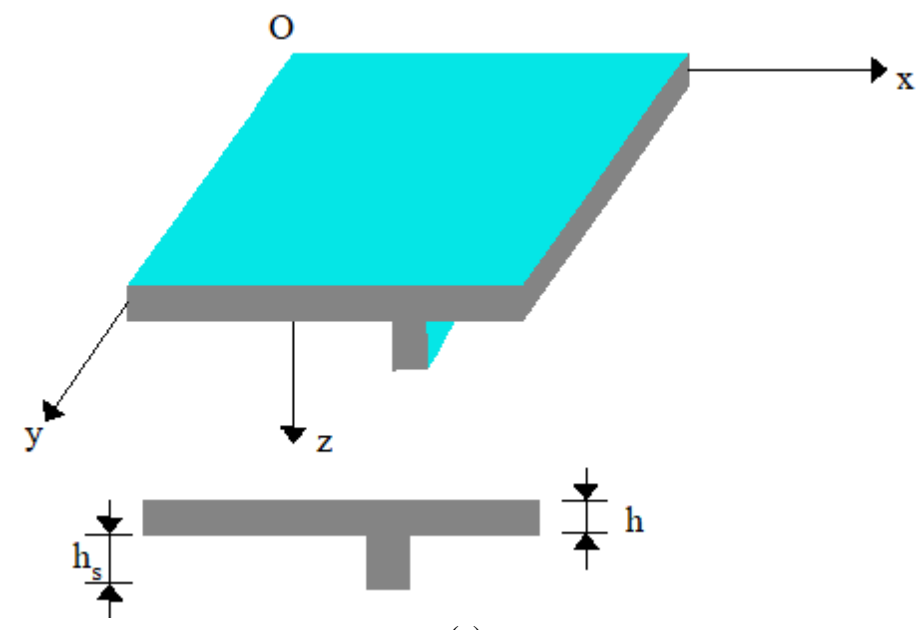

(a)

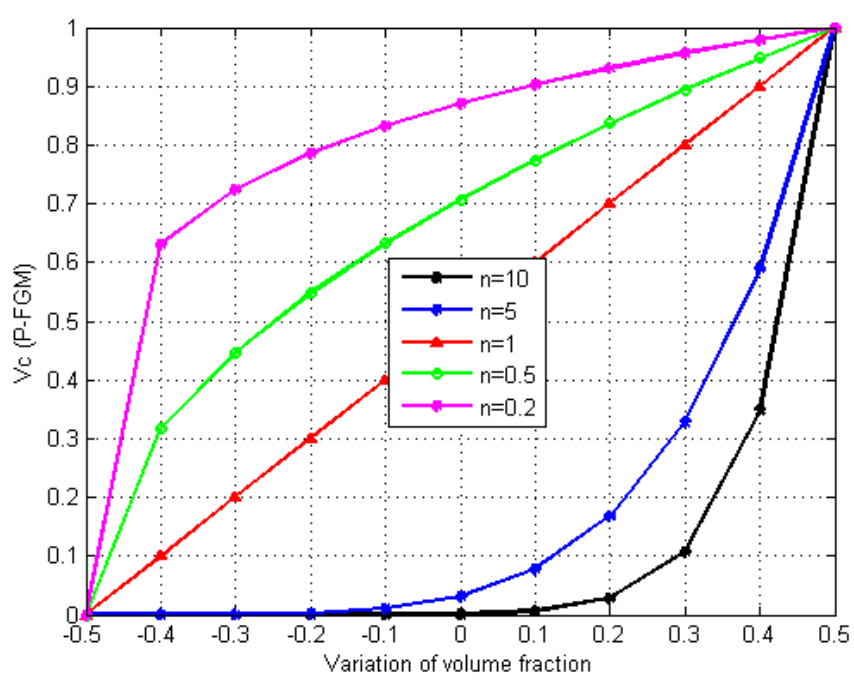

(b)

Fig. 1 (a) The stiffened functionally graded plate and (b) the variation of volume fraction

The volume fraction of ceramic $\left(V_{c}\right)$ and metal $\left(V_{m}\right)$ are formulated in Eq. (1) and the variation of volume fraction for several volume fraction coefficients of a functionally graded plate using the power-law distribution is plotted by Fig.1b. 


$$
V_{c}=\left(\frac{z}{h}+\frac{1}{2}\right)^{n} \quad V_{m}=1-V_{c} \quad n \geq 0
$$

where $z$ is the thickness coordinate variable with $-h / 2 \leq z \leq h / 2$ as well as $c, m$ and $n$ represent the ceramic, metal constituents and the non-negative volume fraction gradient index, respectively. All values of $E, \rho, v$ and $\alpha$ that vary through the thickness of plate are also formulated as below

$$
\begin{aligned}
& E(z)=E_{m}+\left(E_{c}-E_{m}\right)\left(\frac{1}{2}+\frac{z}{h}\right)^{n} \\
& \rho(z)=\rho_{m}+\left(\rho_{c}-\rho_{m}\right)\left(\frac{1}{2}+\frac{z}{h}\right)^{n} \\
& v(z)=v_{m}+\left(v_{c}-v_{m}\right)\left(\frac{1}{2}+\frac{z}{h}\right)^{n} \\
& \alpha(z)=\alpha_{m}+\left(\alpha_{c}-\alpha_{m}\right)\left(\frac{1}{2}+\frac{z}{h}\right)^{n}
\end{aligned}
$$

According to the new theory of Shi [36], a three-dimensional displacement field $(u, v, w)$ was given as below

$$
\begin{gathered}
u(x, y, z)=u_{0}(x, y)+\frac{5}{4}\left(z-\frac{4}{3 h^{2}} z^{3}\right) \phi_{x}(x, y)+\left(\frac{1}{4} z-\frac{5}{3 h^{2}} z^{3}\right) w_{0, x}(x, y) \\
v(x, y, z)=v_{0}(x, y)+\frac{5}{4}\left(z-\frac{4}{3 h^{2}} z^{3}\right) \phi_{y}(x, y)+\left(\frac{1}{4} z-\frac{5}{3 h^{2}} z^{3}\right) w_{0, y}(x, y) \\
w(x, y, z)=w_{0}(x, y)
\end{gathered}
$$

This three-dimensional displacement field can be expressed in terms of the $\mathrm{C} 0$ thirdorder shear deformation theory and seven unknown variables as follows

$$
\begin{gathered}
u(x, y, z)=u_{0}(x, y)+\left(\frac{1}{4} z-\frac{5}{3 h^{2}} z^{3}\right) \phi_{x}^{b}(x, y)+\frac{5}{4}\left(z-\frac{4}{3 h^{2}} z^{3}\right) \phi_{x}^{s}(x, y) \\
v(x, y, z)=v_{0}(x, y)+\left(\frac{1}{4} z-\frac{5}{3 h^{2}} z^{3}\right) \phi_{y}^{b}(x, y)+\frac{5}{4}\left(z-\frac{4}{3 h^{2}} z^{3}\right) \phi_{y}^{s}(x, y) \\
w(x, y, z)=w_{0}(x, y)
\end{gathered}
$$

It can be seen that the present theory is composed of seven unknowns including three axial and transverse displacements, and four rotations due to the bending and shear effects. The strain-displacement relations based on the small strain assumptions can be given as follows 


$$
\left\{\begin{array}{c}
\varepsilon_{x} \\
\varepsilon_{y} \\
\varepsilon_{x y} \\
\gamma_{y z} \\
\gamma_{x z}
\end{array}\right\}=\left\{\begin{array}{c}
u_{0, x}+z \frac{1}{4}\left(5 \phi_{x, x}^{s}+\phi_{x, x}^{b}\right)+z^{3}\left(\frac{-5}{3 h^{2}}\right)\left(\phi_{x, x}^{s}+\phi_{x, x}^{b}\right) \\
v_{0, y}+z \frac{1}{4}\left(5 \phi_{y, y}^{s}+\phi_{y, y}^{b}\right)+z^{3}\left(\frac{-5}{3 h^{2}}\right)\left(\phi_{y, y}^{s}+\phi_{y, y}^{b}\right) \\
u_{0, y}+v_{0, x}+z \frac{1}{4}\left(5 \phi_{x, y}^{s}+5 \phi_{y, x}^{s}+\phi_{x, y}^{b}+\phi_{y, x}^{b}\right)+z^{3}\left(\frac{-5}{3 h^{2}}\right)\left(\phi_{x, y}^{s}+\phi_{y, x}^{s}+\phi_{x, y}^{b}+\phi_{y, x}^{b}\right) \\
\left(\frac{5}{4} \phi_{y}^{s}+\frac{1}{4} \phi_{y}^{b}+w_{, y}\right)+z^{2}\left(\frac{-5}{h^{2}}\right)\left(\phi_{y}^{s}+\phi_{y}^{b}\right) \\
\left(\frac{5}{4} \phi_{x}^{s}+\frac{1}{4} \phi_{x}^{b}+w_{, x}\right)+z^{2}\left(\frac{-5}{h^{2}}\right)\left(\phi_{x}^{s}+\phi_{x}^{b}\right)
\end{array}\right\}
$$

or matrix form

$$
\left\{\begin{array}{l}
\boldsymbol{\varepsilon} \\
\boldsymbol{\gamma}
\end{array}\right\}=\left\{\begin{array}{c}
\boldsymbol{\varepsilon}^{(0)} \\
\boldsymbol{\gamma}^{(0)}
\end{array}\right\}+z\left\{\begin{array}{c}
\boldsymbol{\varepsilon}^{(1)} \\
0
\end{array}\right\}+z^{2}\left\{\begin{array}{c}
0 \\
\boldsymbol{\gamma}^{(2)}
\end{array}\right\}+z^{3}\left\{\begin{array}{c}
\boldsymbol{\varepsilon}^{(3)} \\
0
\end{array}\right\}
$$

with the membrane strains obtained from

$$
\boldsymbol{\varepsilon}^{(0)}=\boldsymbol{\varepsilon}^{(L)}+\boldsymbol{\varepsilon}^{(N L)}=\left\{\begin{array}{c}
\frac{\partial u_{0}}{\partial x} \\
\frac{\partial v_{0}}{\partial y} \\
\frac{\partial u_{0}}{\partial y}+\frac{\partial v_{0}}{\partial x}
\end{array}\right\}+\frac{1}{2}\left[\begin{array}{cc}
\frac{\partial w_{0}}{\partial x} & 0 \\
0 & \frac{\partial w_{0}}{\partial y} \\
\frac{\partial w_{0}}{\partial y} & \frac{\partial w_{0}}{\partial x}
\end{array}\right]\left[\begin{array}{c}
\frac{\partial w_{0}}{\partial x} \\
\frac{\partial w_{0}}{\partial y}
\end{array}\right]
$$

The bending strains are given by

$$
\boldsymbol{\varepsilon}^{(1)}=\frac{1}{4}\left\{\begin{array}{c}
\left(5 \phi_{x, x}^{s}+\phi_{x, x}^{b}\right) \\
\left(5 \phi_{y, y}^{s}+\phi_{y, y}^{b}\right) \\
\left(5 \phi_{x, y}^{s}+5 \phi_{y, x}^{s}+\phi_{x, y}^{b}+\phi_{y, x}^{b}\right)
\end{array}\right\} \quad \boldsymbol{\varepsilon}^{(3)}=\frac{-5}{3 h^{2}}\left\{\begin{array}{c}
\phi_{x, x}^{s}+\phi_{x, x}^{b} \\
\phi_{y, y}^{s}+\phi_{y, y}^{b} \\
\phi_{x, y}^{s}+\phi_{y, x}^{s}+\phi_{x, y}^{b}+\phi_{y, x}^{b}
\end{array}\right\}
$$

And the shear strains are basically written by

$$
\gamma^{(0)}=\left\{\begin{array}{l}
\frac{5}{4} \phi_{y}^{s}+\frac{1}{4} \phi_{y}^{b}+w_{, y} \\
\frac{5}{4} \phi_{x}^{s}+\frac{1}{4} \phi_{x}^{b}+w_{, x}
\end{array}\right\} \quad \gamma^{(2)}=\frac{-5}{h^{2}}\left\{\begin{array}{l}
\phi_{y}^{s}+\phi_{y}^{b} \\
\phi_{x}^{s}+\phi_{x}^{b}
\end{array}\right\}
$$

The membrane, bending and shear strains can be then expressed as

$$
\boldsymbol{\varepsilon}^{(L)}=\sum_{i=1}^{4} \mathbf{B}_{1 i}^{L} \mathbf{q}_{i} \quad \boldsymbol{\varepsilon}^{(N L)}=\frac{1}{2} \sum_{i=1}^{4} \mathbf{B}_{1 i}^{N L} \mathbf{q}_{i} \quad \boldsymbol{\varepsilon}^{(1)}=\sum_{i=1}^{4} \mathbf{B}_{2 i} \mathbf{q}_{i} \quad \boldsymbol{\varepsilon}^{(3)}=\sum_{i=1}^{4} \mathbf{B}_{3 i} \mathbf{q}_{i}
$$




$$
\boldsymbol{\gamma}^{(0)}=\sum_{i=1}^{4} \mathbf{B}_{4 i} \mathbf{q}_{i} \quad \boldsymbol{\gamma}^{(2)}=\sum_{i=1}^{4} \mathbf{B}_{5 i} \mathbf{q}_{i}
$$

in which

$$
\begin{aligned}
& \mathbf{B}_{1 i}^{L}=\left[\begin{array}{ccccccc}
N_{i, x} & 0 & 0 & 0 & 0 & 0 & 0 \\
0 & N_{i, y} & 0 & 0 & 0 & 0 & 0 \\
N_{i, y} & N_{i, x} & 0 & 0 & 0 & 0 & 0
\end{array}\right] \mathbf{B}_{2 i}=\frac{1}{4}\left[\begin{array}{ccccccc}
0 & 0 & 0 & 5 N_{i, x} & 0 & N_{i, x} & 0 \\
0 & 0 & 0 & 0 & 5 N_{i, y} & 0 & N_{i, y} \\
0 & 0 & 0 & 5 N_{i, y} & 5 N_{i, x} & N_{i, y} & N_{i, x}
\end{array}\right] \\
& \mathbf{B}_{3 i}=-\frac{5}{3 h^{2}}\left[\begin{array}{ccccccc}
0 & 0 & 0 & N_{i, x} & 0 & N_{i, x} & 0 \\
0 & 0 & 0 & 0 & N_{i, y} & 0 & N_{i, y} \\
0 & 0 & 0 & N_{i, y} & N_{i, x} & N_{i, y} & N_{i, x}
\end{array}\right] \mathbf{B}_{4 i}=\left[\begin{array}{ccccccc}
0 & 0 & N_{i, y} & 0 & \frac{5}{4} & 0 & \frac{1}{4} \\
0 & 0 & N_{i, x} & \frac{5}{4} & 0 & \frac{1}{4} & 0
\end{array}\right] \\
& \mathbf{B}=-\frac{5}{h}\left[\begin{array}{lllllll}
0 & 0 & 0 & 0 & 1 & 0 & 1 \\
0 & 0 & 0 & 1 & 0 & 1 & 0
\end{array}\right] \quad \mathbf{B}_{1 i}^{N L}=\left[\begin{array}{ccccccc}
\frac{\partial w_{0}}{\partial x} & 0 & \frac{\partial w_{0}}{\partial y} & 0 & 0 & 0 & 0 \\
0 & \frac{\partial w_{0}}{\partial y} & \frac{\partial w_{0}}{\partial x} & 0 & 0 & 0 & 0
\end{array}\right]^{T} \times \\
& \times\left[\begin{array}{lllllll}
0 & 0 & N_{i, x} & 0 & 0 & 0 & 0 \\
0 & 0 & N_{i, y} & 0 & 0 & 0 & 0
\end{array}\right]
\end{aligned}
$$

where $N_{i}, N_{i, x}$ and $N_{i, y}$ are called the shape function and two derivatives of it in $x$-direction and $y$-direction.

The global stiffness matrix is computed by

$$
\mathbf{K}=\mathbf{K}_{L}+\mathbf{K}_{N L}+\mathbf{K}_{G}
$$

The element linear stiffness matrix

$$
\mathbf{K}_{L, e}=\int_{\Omega_{e}}\left(\mathbf{B}_{i}^{T} \mathbf{D}^{*} \mathbf{B}_{j}+\mathbf{S}_{i}^{T} \mathbf{D}_{s}^{*} \mathbf{S}_{j}\right) d \Omega
$$

with

$$
\mathbf{B}_{i}=\left[\begin{array}{lll}
\left(\mathbf{B}_{1 i}^{L}\right)^{T} & \left(\mathbf{B}_{2 i}\right)^{T} & \left(\mathbf{B}_{3 i}\right)^{T}
\end{array}\right] \quad \mathbf{S}_{i}=\left[\begin{array}{ll}
\left(\mathbf{B}_{4 i}\right)^{T} & \left(\mathbf{B}_{5 i}\right)^{T}
\end{array}\right]
$$

And the element nonlinear stiffness matrix

$$
\mathbf{K}_{N L, e}=\int_{\Omega_{e}}\left(\frac{1}{2} \mathbf{B}_{L i}^{T} \mathbf{D}^{* *} \mathbf{B}_{L j}+\mathbf{B}_{N L i}^{T} \mathbf{D}^{* *} \mathbf{B}_{L j}+\frac{1}{2} \mathbf{B}_{N L i}^{T} \mathbf{D}^{* *} \mathbf{B}_{N L j}\right) d \Omega
$$

where

$$
\mathbf{B}_{L i}=\left[\begin{array}{ll}
\mathbf{B}_{i} & \mathbf{S}_{i}
\end{array}\right]^{T} \quad \mathbf{B}_{N L i}=\left[\begin{array}{ll}
\mathbf{B}_{1 i}^{N L} & 0
\end{array}\right]^{T} \quad \mathbf{D}^{* *}=\left[\begin{array}{cc}
\mathbf{D}^{*} & 0 \\
0 & \mathbf{D}_{s}^{*}
\end{array}\right]
$$


On the other hand, the element geometric stiffness matrix

$$
\mathbf{K}_{G, e}=\int_{\Omega_{e}}\left(\mathbf{G}_{i}^{T} \overline{\mathbf{N}} \mathbf{G}_{j}\right) d \Omega
$$

with

$$
\mathbf{G}_{i}=\left[\begin{array}{lllllll}
0 & 0 & N_{i, x} & 0 & 0 & 0 & 0 \\
0 & 0 & N_{i, y} & 0 & 0 & 0 & 0
\end{array}\right] \quad \overline{\mathbf{N}}=\left[\begin{array}{cc}
N_{x} & N_{x y} \\
N_{x y} & N_{y}
\end{array}\right]
$$

Let us consider that the addition of the stiffener is in the $x$-direction and by transforming three Eqs. (6-8) as follows

$$
\begin{gathered}
u_{s t}(x, y, z)=u_{0 s t}(x, y)+\left(\frac{1}{4} z-\frac{5}{3 h^{2}} z^{3}\right) \phi_{x s t}^{b}(x, y)+\frac{5}{4}\left(z-\frac{4}{3 h^{2}} z^{3}\right) \phi_{x s t}^{s}(x, y) \\
v_{s t}(x, y, z)=0 \\
w_{s t}(x, y, z)=w_{0 s t}(x, y)
\end{gathered}
$$

Only the plate elements having an edge coinciding with the stiffener are considered; the establishment of formulation is quite similar. The global stiffness matrix for the stiffener is given by

$$
\mathbf{K}_{s t}=\mathbf{K}_{L s t}+\mathbf{K}_{N L s t}+\mathbf{K}_{G s t}
$$

The correlation of the displacements between the plate and the stiffener are presented in matrix form as

$$
\left\{\begin{array}{c}
u_{0 s t} \\
0 \\
w_{0 s t} \\
\phi_{x s t}^{s} \\
0 \\
\phi_{x s t}^{b} \\
0
\end{array}\right\}=\left[\begin{array}{ccccccc}
1 & 0 & 0 & e & 0 & e & 0 \\
0 & 0 & 0 & 0 & 0 & 0 & 0 \\
0 & 0 & 1 & 0 & 0 & 0 & 0 \\
0 & 0 & 0 & 1 & 0 & 0 & 0 \\
0 & 0 & 0 & 0 & 0 & 0 & 0 \\
0 & 0 & 0 & 0 & 0 & 1 & 0 \\
0 & 0 & 0 & 0 & 0 & 0 & 0
\end{array}\right]\left\{\begin{array}{c}
u_{0} \\
v_{0} \\
w_{0} \\
\phi_{x}^{s} \\
\phi_{y}^{s} \\
\phi_{x}^{b} \\
\phi_{y}^{b}
\end{array}\right\}
$$

where $e=\left(h+h_{s}\right) / 2$ is the eccentricity between the plate and the stiffener, respectively.

Besides, the mass matrix of plate element is shown

$$
\mathbf{M}_{e}=\int_{V_{e}} \mathbf{N}^{T} \mathbf{L}^{T} \rho(z) \mathbf{L} \mathbf{N} d V=\int_{S_{e}} \mathbf{N}^{T}\left(\int_{-h / 2}^{h / 2} \rho(z) \mathbf{L}^{T} \mathbf{L} d z\right) \mathbf{N} d S
$$

with 


$$
\mathbf{L}=\left[\begin{array}{ccccc}
1 & 0 & \left(\frac{1}{4} z-\frac{5}{3 h^{2}} z^{3}\right) \frac{\partial}{\partial x} & \frac{5}{4}\left(z-\frac{4}{3 h^{2}} z^{3}\right) & 0 \\
0 & 1 & \left(\frac{1}{4} z-\frac{5}{3 h^{2}} z^{3}\right) \frac{\partial}{\partial y} & 0 & \frac{5}{4}\left(z-\frac{4}{3 h^{2}} z^{3}\right) \\
0 & 0 & 1 & 0 & 0
\end{array}\right]
$$

and exactly the same way for the stiffener element

$$
\mathbf{M}_{e s t}=\int_{V_{e s t}} \mathbf{N}^{T} \mathbf{L}_{s t}^{L} \rho(z) \mathbf{L}_{s t} \mathbf{N} d V=\int_{S_{e s t}} \mathbf{N}^{T}\left(\int_{-h_{s t} / 2}^{h_{s t} / 2} \rho(z) \mathbf{L}_{s t}^{L} \mathbf{L}_{s t} d z\right) \mathbf{N} d S
$$

with

$$
\mathbf{L}=\left[\begin{array}{ccccc}
1 & 0 & \left(\frac{1}{4} z-\frac{5}{3 h^{2}} z^{3}\right) \frac{\partial}{\partial x} & \frac{5}{4}\left(z-\frac{4}{3 h^{2}} z^{3}\right) & 0 \\
0 & 0 & 0 & 0 & 0 \\
0 & 0 & 1 & 0 & 0
\end{array}\right]
$$

For vibration of the stiffened functionally graded plate, the equation can be described as

$$
\begin{gathered}
\left(\mathbf{M}+\mathbf{M}_{s t}\right) \ddot{\mathbf{q}}+\left(\mathbf{K}+\mathbf{K}_{s t}\right) \mathbf{q}=\mathbf{0} \\
{\left[\left(\mathbf{K}+\mathbf{K}_{s t}\right)-\omega^{2}\left(\mathbf{M}+\mathbf{M}_{s t}\right)\right] \mathbf{q}=\mathbf{0}}
\end{gathered}
$$

\section{NUMERICAL RESULTS}

In this section, the numerical solutions for the nonlinear free vibration analysis of stiffened functionally graded plates are presented. Not only the fully simply supported but also the fully clamped boundary conditions are used in this paper.

The fully simply supported boundary conditions (SSSS) for this procedure

$$
v_{0}=w_{0}=\phi_{y}^{s}=\phi_{y}^{b}=0 \text {, at } x=0, a \text { and } u_{0}=w_{0}=\phi_{x}^{s}=\phi_{x}^{b}=0 \text {, at } y=0, b
$$

and the fully clamped boundary conditions (CCCC)

$$
u_{0}=v_{0}=w_{0}=\phi_{x}^{s}=\phi_{x}^{b}=\phi_{y}^{s}=\phi_{y}^{b} \text { at } x=0, a \text { and } y=0, b
$$


Table 1 Material properties of the plate and the stiffener

\begin{tabular}{c}
\hline Material I \\
$E=3 \times 10^{7} \mathrm{~Pa}, v=0.3$ and $\rho=2820 \mathrm{~kg} / \mathrm{m}^{3}$ \\
Material II \\
$E=211 \times 10^{9} \mathrm{~Pa}, v=0.3$ and $\rho=7830 \mathrm{~kg} / \mathrm{m}^{3}$ \\
\hline Material III \\
$E_{m}=322.7 \times 10^{9} \mathrm{~Pa}, v_{m}=0.28, \rho_{m}=2370 \mathrm{~kg} / \mathrm{m}^{3}, E_{c}=207.79 \times 10^{9} \mathrm{~Pa}, v_{c}=0.28$, \\
$\rho_{c}=8166 \mathrm{~kg} / \mathrm{m}^{3}$
\end{tabular}

\subsection{Verification}

Firstly, the fully simply supported rectangular plate with two stiffeners as depicted in Fig. 2 is studied in order to verify reliability and validity of the proposed method. The material properties are material I as $E=3 \times 10^{7} \mathrm{~Pa}, v=0.3$ and $\rho=2820 \mathrm{~kg} / \mathrm{m}^{3}$ in Table 1 for both the plate and the stiffener. The first five natural frequencies are given in Table 2 and compared with the solutions of Peng et al. [19] as well as the results from Ansys software. It can be seen that the values presented in this paper have a good agreement with the references.

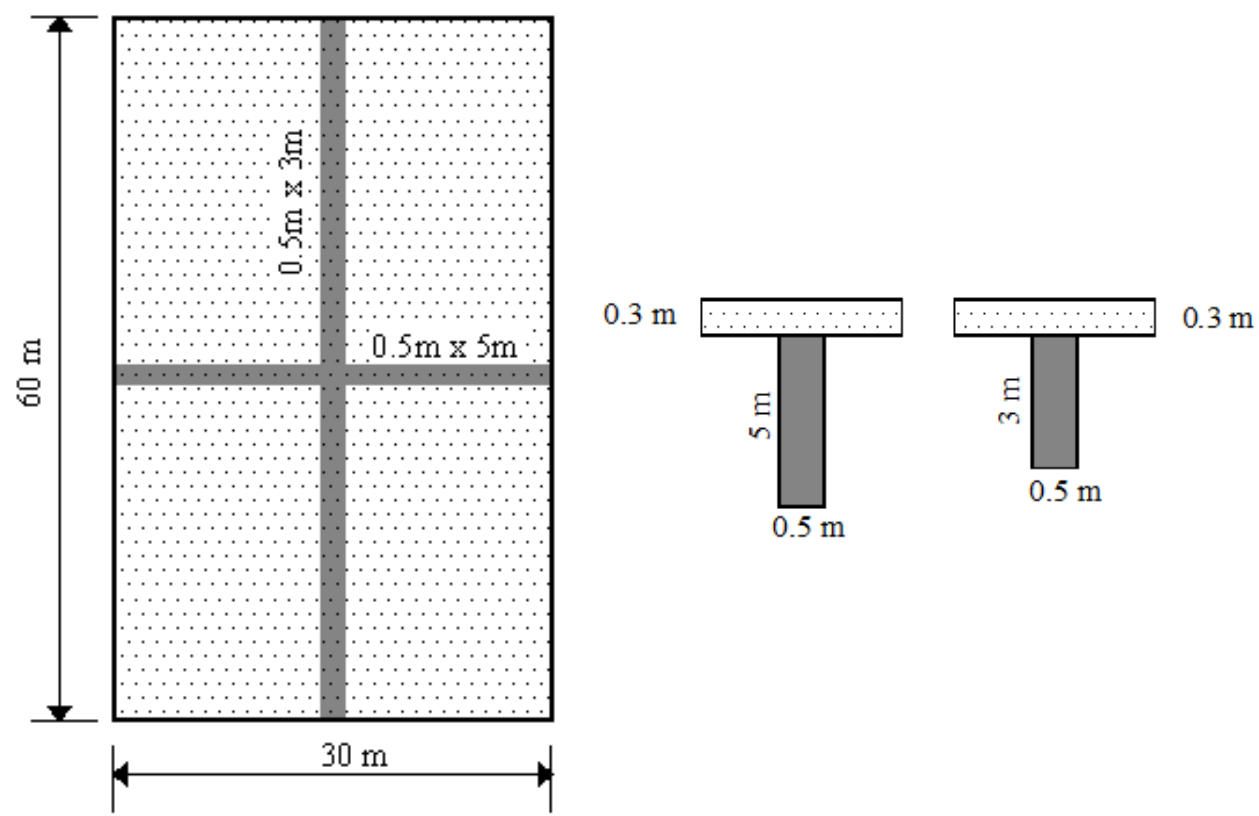

Fig. 2 The geometric properties of the stiffened rectangular plate with two stiffeners perpendicular to each other

Next, the other fully simply supported rectangular plate with one stiffener in the middle is considered. The geometric properties of the plate are $a=0.6 \mathrm{~m}, b=0.41 \mathrm{~m}$ and $h$ $=0.00633 \mathrm{~m}$. 
Table 2 The comparison of first five natural frequencies $(\mathrm{Hz})$ of the fully simply supported rectangular with two stiffeners

\begin{tabular}{lccccc}
\hline Results & \multicolumn{5}{c}{ Mode } \\
\cline { 2 - 6 } & 1 & 2 & 3 & 4 & 5 \\
\hline Ansys & 0.0812 & 0.0849 & 0.1035 & 0.1090 & 0.1292 \\
L. X. Peng et al. [19] & 0.0816 & 0.0856 & 0.1000 & 0.1028 & 0.1311 \\
Present & 0.0819 & 0.0861 & 0.1055 & 0.1104 & 0.1320 \\
\hline
\end{tabular}

Table 3 The comparison of first three natural frequencies $(H z)$ of the fully simply supported rectangular with one stiffener

\begin{tabular}{lccc}
\hline Results & \multicolumn{3}{c}{ Mode } \\
\cline { 2 - 4 } & 1 & 2 & 3 \\
\hline Mukherjee et al. [37] & 257.05 & 272.10 & 524.70 \\
Harik et al. [38] & 253.59 & 282.02 & 513.50 \\
Aksu et al. [2] & 254.94 & 269.46 & 511.64 \\
Dayi Ou et al. [39] & 258.79 & 273.89 & 527.29 \\
Present & 259.47 & 283.72 & 525.30 \\
\hline
\end{tabular}

Furthermore, the geometric properties of the stiffener along edge $b$ of plate are $h_{s}=$ $0.0222 \mathrm{~m}$ and $b_{s}=0.001277 \mathrm{~m}$. The material properties are material II with $E=211 \times 10^{9}$ Pa, $v=0.3$ and $\rho=7830 \mathrm{~kg} / \mathrm{m}^{3}$ as Table 1 for both the plate and the stiffener. The first three natural frequencies based on the proposed method are compared with the others related to Mukherjee et al. [37], Harik et al. [38], Aksu et al. [2] and Dayi et al. [39]. From Table 3, it is interesting to note that the obtained numerical solutions match very well with the others.

The last example in this section is related to the nonlinear free vibration analysis for a fully simply supported functionally graded $\mathrm{Si}_{3} \mathrm{~N}_{4} / \mathrm{SUS} 304$ square plate with $a=b=0.4 \mathrm{~m}$ and thickness $h=0.005 \mathrm{~m}$. The material properties are material III with $E_{m}=322.7 \times 10^{9}$ $\mathrm{Pa}, v_{m}=0.28, \rho_{m}=2370 \mathrm{~kg} / \mathrm{m}^{3}, E_{c}=207.79 \times 10^{9} \mathrm{~Pa}, v_{c}=0.28, \rho_{c}=8166 \mathrm{~kg} / \mathrm{m}^{3}$. The nonlinear to linear frequency ratios $\omega_{N L} / \omega_{L}$ with $n=2$ as given in Table 4 are compared with the results of Shen [40]. Once again, the accuracy and efficiency of the proposed method are proved by the very small errors between the results of two methods.

Table 4 The nonlinear to linear frequency ratio $\omega_{N L} / \omega_{L}$ of the fully simply supported square functionally graded plate

\begin{tabular}{lcccccc}
\hline$n=2$ & \multicolumn{7}{c}{$w_{\max } / h$} \\
\cline { 2 - 7 } Results & 0.0 & 0.2 & 0.4 & 0.6 & 0.8 & 1 \\
\hline H. S. Shen [40] & 1.00 & 1.021 & 1.081 & 1.174 & 1.293 & 1.432 \\
Present & 1.00 & 1.020 & 1.079 & 1.169 & 1.278 & 1.414 \\
\hline
\end{tabular}




\subsection{Verification of the nonlinear free vibration of functionally graded plate with one stiffener}

By adding one stiffener in the middle as illustrated in Fig. 3 for the functionally graded $\mathrm{Si}_{3} \mathrm{~N}_{4} / \mathrm{SUS} 304$ square plate as example above with $a / h=10$ and 20 , the nonlinear to linear frequency ratios $\omega_{N L} / \omega_{L}$ are calculated.

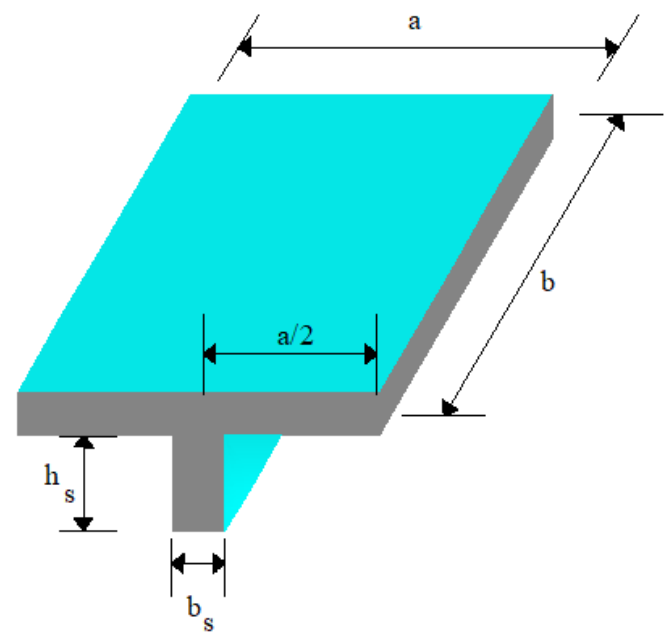

Fig. 3 The stiffened functionally graded plate with one stiffener in the middle

The correlations of geometry between the plate and the stiffener are introduced as $b_{s}$ $=a / 30, h_{s}=5 h$ or $b_{s}=a / 50, h_{s}=5 h$. Two types of boundary condition and six values of $n$ $(0,0.5,1,2,5$ and 10$)$ are also used in this example.

The numerical results based on this proposed method are given in Tables 5-12 and displayed in Figs. 4-7. We have found out that the nonlinear to linear frequency ratios $\omega_{N L} / \omega_{L}$ decrease with increasing the volume fraction coefficient $n$.

This order does not change when we change ratio $a / h$ or the boundary conditions.

Besides, the first four mode shapes for fully simply supported stiffened functionally graded plate with case $a / h=10, b_{s}=a / 30$ and $n=2$ are also depicted in Fig. 8 .

Table 5 Nonlinear to linear frequency ratio $\omega_{N L} / \omega_{L}$ of (SSSS) square FGM stiffened plate with one stiffener $\left(b_{s}=a / 30, h_{s}=5 h\right.$ and $\left.a / h=10\right)$

\begin{tabular}{ccccccc}
\hline$a / h$ & $n$ & \multicolumn{5}{c}{$($ SSSS $)$} \\
\cline { 3 - 6 } & & 0.2 & 0.4 & 0.6 & 0.8 & 1.0 \\
\hline 10 & 0 & 1.0211 & 1.0491 & 1.0828 & 1.1213 & 1.1543 \\
& 0.5 & 1.0197 & 1.0461 & 1.0777 & 1.1139 & 1.1536 \\
& 1 & 1.0191 & 1.0443 & 1.0748 & 1.1095 & 1.1475 \\
& 2 & 1.0184 & 1.0426 & 1.0717 & 1.1048 & 1.1411 \\
& 5 & 1.0178 & 1.0410 & 1.0688 & 1.1005 & 1.1350 \\
& 10 & 1.0176 & 1.0404 & 1.0678 & 1.0988 & 1.1328 \\
\hline
\end{tabular}


Table 6 Nonlinear to linear frequency ratio $\omega_{N L} / \omega_{L}$ of (SSSS) square FGM stiffened plate with one stiffener $\left(b_{s}=a / 30, h_{s}=5 h\right.$ and $\left.a / h=20\right)$

\begin{tabular}{ccccccc}
\hline$a / h$ & $n$ & \multicolumn{5}{c}{$(\mathrm{SSSS})$} \\
\cline { 2 - 6 } & & 0.2 & 0.4 & 0.6 & 0.8 & 1.0 \\
\hline 20 & 0 & 1.0210 & 1.0473 & 1.0772 & 1.1107 & 1.1470 \\
& 0.5 & 1.0194 & 1.0432 & 1.0706 & 1.1012 & 1.1344 \\
& 1 & 1.0183 & 1.0407 & 1.0667 & 1.0956 & 1.1269 \\
& 2 & 1.0173 & 1.0384 & 1.0629 & 1.0902 & 1.1195 \\
& 5 & 1.0164 & 1.0364 & 1.0594 & 1.0851 & 1.1127 \\
& 10 & 1.0160 & 1.0354 & 1.0578 & 1.0828 & 1.1048 \\
\hline
\end{tabular}

Table 7 Nonlinear to linear frequency ratio $\omega_{N L} / \omega_{L}$ of (CCCC) square FGM stiffened plate with one stiffener $\left(b_{s}=a / 30, h_{s}=5 h\right.$ and $\left.a / h=10\right)$

\begin{tabular}{ccccccc}
\hline$a / h$ & $n$ & \multicolumn{5}{c}{$w_{\text {central }} / h$} \\
\cline { 3 - 6 } & & 0.2 & 0.4 & 0.6 & 0.8 & 1.0 \\
\hline 10 & 0 & 1.0032 & 1.0114 & 1.0242 & 1.0415 & 1.0625 \\
& 0.5 & 1.0029 & 1.0106 & 1.0227 & 1.0390 & 1.0590 \\
& 1 & 1.0027 & 1.0100 & 1.0217 & 1.0374 & 1.0566 \\
& 2 & 1.0025 & 1.0095 & 1.0206 & 1.0355 & 1.0539 \\
& 5 & 1.0024 & 1.0089 & 1.0195 & 1.0337 & 1.0511 \\
& 10 & 1.0023 & 1.0087 & 1.0190 & 1.0329 & 1.0501 \\
\hline
\end{tabular}

Table 8 Nonlinear to linear frequency ratio $\omega_{N L} / \omega_{L}$ of (CCCC) square FGM stiffened plate with one stiffener $\left(b_{s}=a / 30, h_{s}=5 h\right.$ and $\left.a / h=20\right)$

\begin{tabular}{ccccccc}
\hline$a / h$ & $n$ & \multicolumn{5}{c}{$w_{\text {central }} / h$} \\
\cline { 3 - 6 } & & 0.2 & 0.4 & 0.6 & 0.8 & 1.0 \\
\hline 20 & 0 & 1.0019 & 1.0066 & 1.0138 & 1.0236 & 1.0358 \\
& 0.5 & 1.0013 & 1.0050 & 1.0112 & 1.0197 & 1.0304 \\
& 1 & 1.0009 & 1.0042 & 1.0098 & 1.0176 & 1.0275 \\
& 2 & 1.0007 & 1.0036 & 1.0086 & 1.0157 & 1.0248 \\
& 5 & 1.0005 & 1.0030 & 1.0075 & 1.0140 & 1.0224 \\
& 10 & 1.0003 & 1.0027 & 1.0070 & 1.0132 & 1.0212 \\
\hline
\end{tabular}

Table 9 Nonlinear to linear frequency ratio $\omega_{N L} / \omega_{L}$ of (SSSS) square FGM stiffened plate with one stiffener $\left(b_{s}=a / 50, h_{s}=5 h\right.$ and $\left.a / h=10\right)$

\begin{tabular}{ccccccc}
\hline$a / h$ & $n$ & \multicolumn{5}{c}{$(\mathrm{SSSS})$} \\
\cline { 3 - 6 } & & 0.2 & 0.4 & 0.6 & 0.8 & 1.0 \\
\hline 10 & 0 & 1.0213 & 1.0502 & 1.0875 & 1.1288 & 1.1793 \\
& 0.5 & 1.0196 & 1.0471 & 1.0822 & 1.1230 & 1.1683 \\
& 1 & 1.0188 & 1.0455 & 1.0792 & 1.1184 & 1.1619 \\
& 2 & 1.0181 & 1.0438 & 1.0761 & 1.1137 & 1.1551 \\
& 5 & 1.0176 & 1.0424 & 1.0734 & 1.1093 & 1.1489 \\
& 10 & 1.0175 & 1.0420 & 1.0725 & 1.1079 & 1.1468 \\
\hline
\end{tabular}




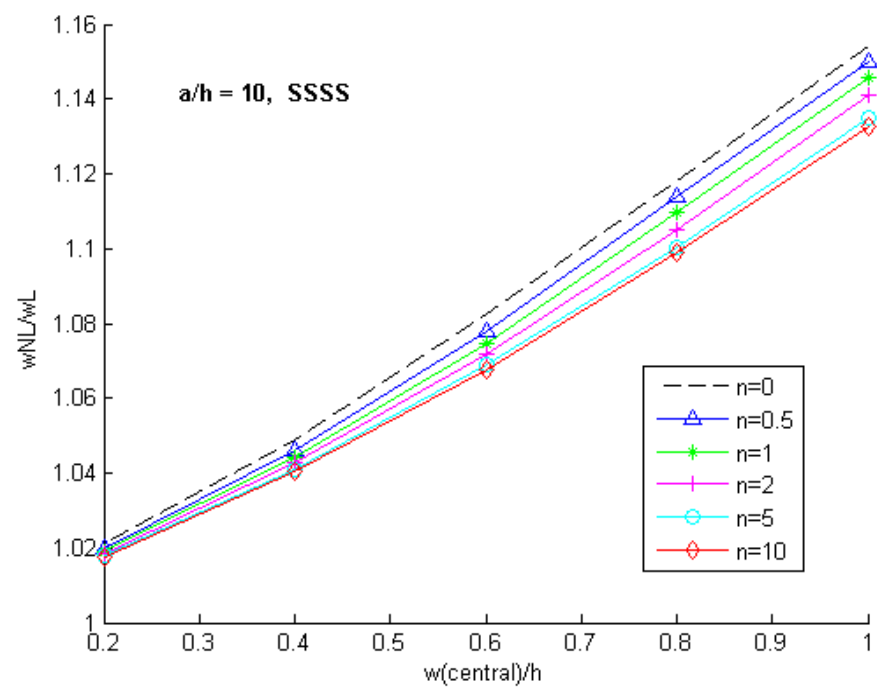

Fig. 4 The effects of $n$ on the nonlinear to linear frequency ratio $\omega_{N L} / \omega_{L}$ for case SSSS with $a / b=1, a / h=10$ and $b_{s}=a / 30, h_{s}=5 h$.

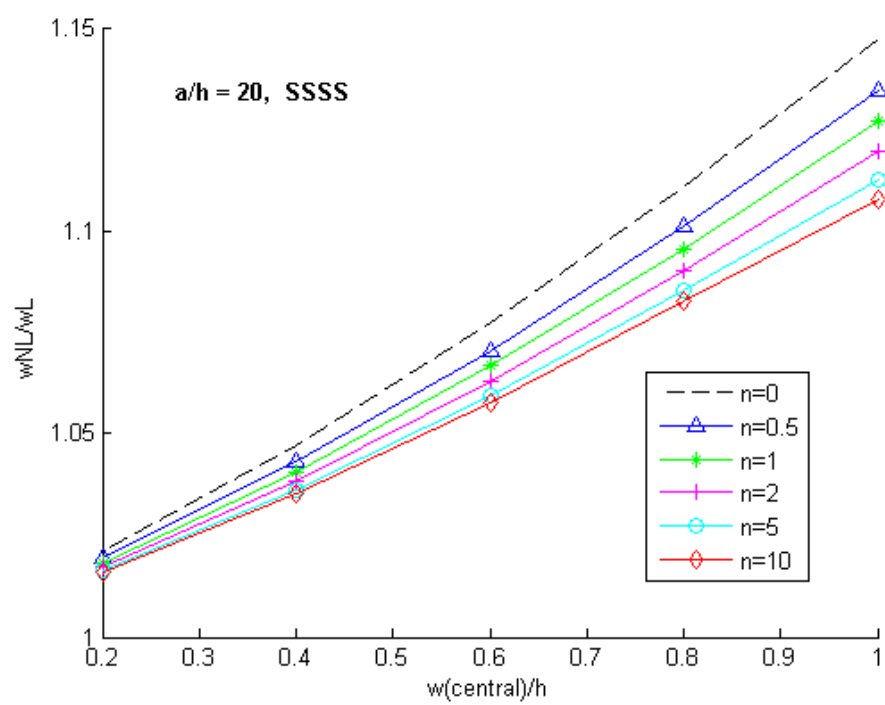

Fig. 5 The effects of $n$ on the nonlinear to linear frequency ratio $\omega_{N L} / \omega_{L}$ for case SSSS with $a / b=1, a / h=20$ and $b_{s}=a / 30, h_{s}=5 h$. 


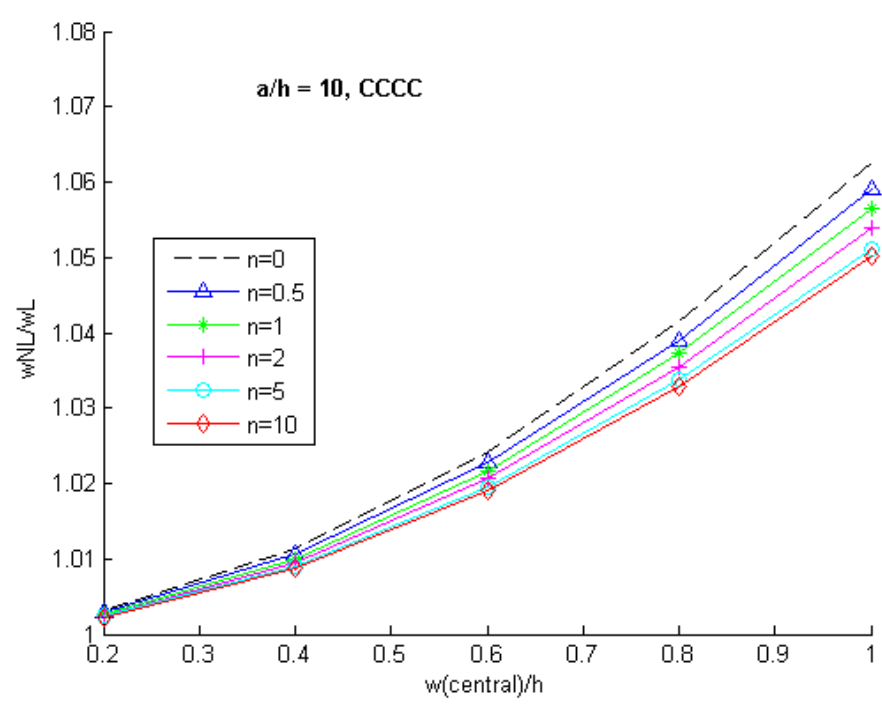

Fig. 6 The effects of $n$ on the nonlinear to linear frequency ratio $\omega_{N L} / \omega_{L}$ for case CCCC with $a / b=1, a / h=10$ and $b_{s}=a / 30, h_{s}=5 h$.

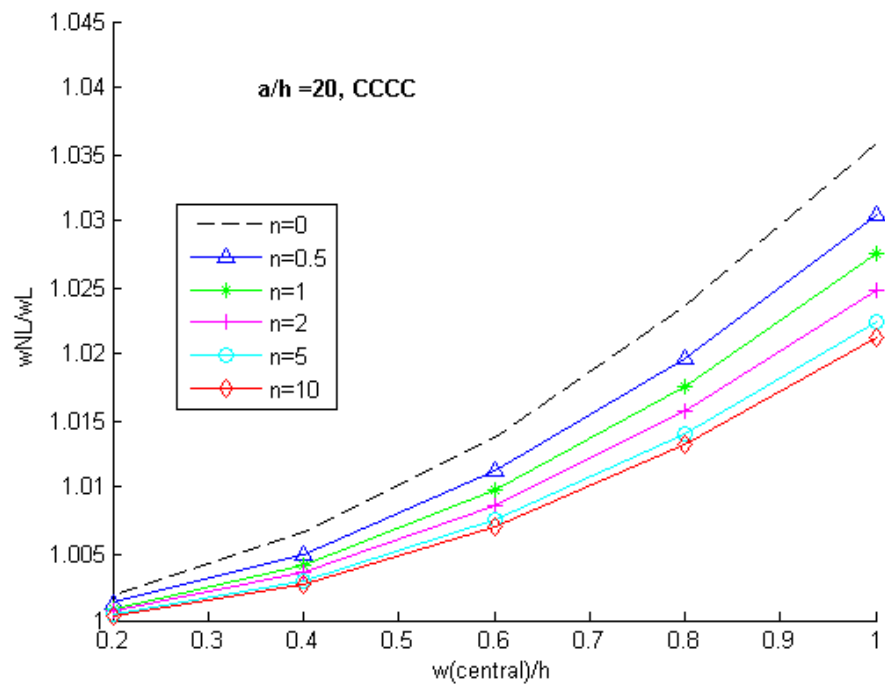

Fig. 7 The effects of $n$ on the nonlinear to linear frequency ratio $\omega_{N L} / \omega_{L}$ for case CCCC with $a / b=1, a / h=20$ and $b_{s}=a / 30, h_{s}=5 h$. 
Table 10 Nonlinear to linear frequency ratio $\omega_{N L} / \omega_{L}$ of (SSSS) square FGM stiffened plate with one stiffener $\left(b_{s}=a / 50, h_{s}=5 h\right.$ and $\left.a / h=20\right)$

\begin{tabular}{ccccccc}
\hline$a / h$ & $n$ & \multicolumn{5}{c}{$($ SSSS $)$} \\
\cline { 2 - 6 } & & 0.2 & 0.4 & 0.6 & 0.8 & 1.0 \\
\hline 20 & 0 & 1.0211 & 1.0486 & 1.0819 & 1.1198 & 1.1614 \\
& 0.5 & 1.0194 & 1.0449 & 1.0756 & 1.1104 & 1.1486 \\
& 1 & 1.0187 & 1.0430 & 1.0722 & 1.1054 & 1.1416 \\
& 2 & 1.0179 & 1.0411 & 1.0690 & 1.1005 & 1.1348 \\
& 5 & 1.0173 & 1.0395 & 1.0660 & 1.0959 & 1.1285 \\
& 10 & 1.0170 & 1.0388 & 1.0647 & 1.0940 & 1.1258 \\
\hline
\end{tabular}

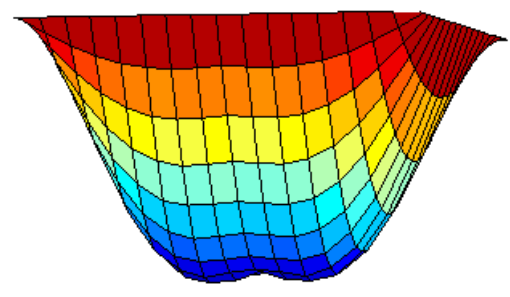

Mode 1

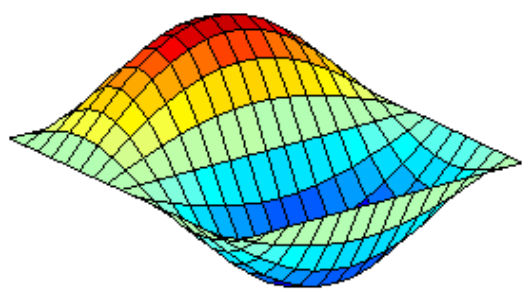

Mode 3

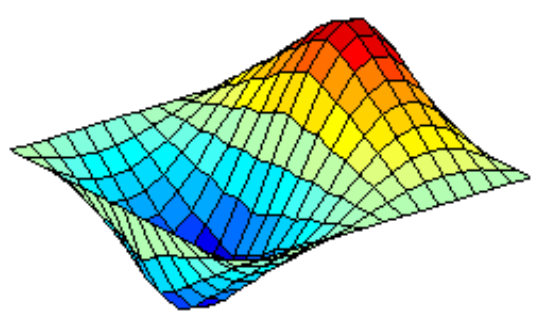

Mode 2

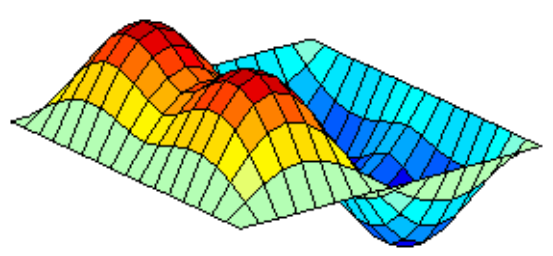

Mode 4

Fig. 8 The first four mode shapes of the stiffened functionally graded plate with one stiffener

Table 11 Nonlinear to linear frequency ratio $\omega_{N L} / \omega_{L}$ of (CCCC) square FGM stiffened plate with one stiffener $\left(b_{s}=a / 50, h_{s}=5 h\right.$ and $\left.a / h=10\right)$

\begin{tabular}{ccccccc}
\hline$a / h$ & $n$ & \multicolumn{5}{c}{$(\mathrm{CCCC})$} \\
\cline { 2 - 6 } & & 0.2 & 0.4 & 0.6 & 0.8 & 1.0 \\
\hline 10 & 0 & 1.0035 & 1.0127 & 1.0272 & 1.0467 & 1.0702 \\
& 0.5 & 1.0032 & 1.0118 & 1.0255 & 1.0438 & 1.0661 \\
& 1 & 1.0030 & 1.0113 & 1.0244 & 1.0420 & 1.0634 \\
& 2 & 1.0028 & 1.0107 & 1.0232 & 1.0399 & 1.0604 \\
& 5 & 1.0027 & 1.0101 & 1.0219 & 1.0378 & 1.0573 \\
& 10 & 1.0026 & 1.0099 & 1.0215 & 1.0371 & 1.0563 \\
\hline
\end{tabular}


Table 12 Nonlinear to linear frequency ratio $\omega_{N L} / \omega_{L}$ of (CCCC) square FGM stiffened plate with one stiffener $\left(b_{s}=a / 50, h_{s}=5 h\right.$ and $\left.a / h=20\right)$

\begin{tabular}{|c|c|c|c|c|c|c|}
\hline \multirow[t]{2}{*}{$a / h$} & \multirow[t]{2}{*}{$n$} & \multicolumn{3}{|c|}{ (CCCC) } & \multicolumn{2}{|c|}{$w_{\text {central }} / h$} \\
\hline & & 0.2 & 0.4 & 0.6 & 0.8 & 1.0 \\
\hline \multirow[t]{6}{*}{20} & 0 & 1.0022 & 1.0078 & 1.0166 & 1.0284 & 1.0431 \\
\hline & 0.5 & 1.0016 & 1.0063 & 1.0138 & 1.0242 & 1.0371 \\
\hline & 1 & 1.0013 & 1.0056 & 1.0126 & 1.0221 & 1.0341 \\
\hline & 2 & 1.0011 & 1.0049 & 1.0114 & 1.0202 & 1.0313 \\
\hline & 5 & 1.0009 & 1.0044 & 1.0103 & 1.0184 & 1.0287 \\
\hline & 10 & 1.0008 & 1.0041 & 1.0098 & 1.0176 & 1.0276 \\
\hline
\end{tabular}

\subsection{Nonlinear free vibration of a functionally graded plate with two stiffeners}

The last example is related to the analysis of functionally graded $\mathrm{Si}_{3} \mathrm{~N}_{4} / \mathrm{SUS} 304$ square plate with two stiffeners perpendicular to each other in the middle as illustrated in Fig. 9.

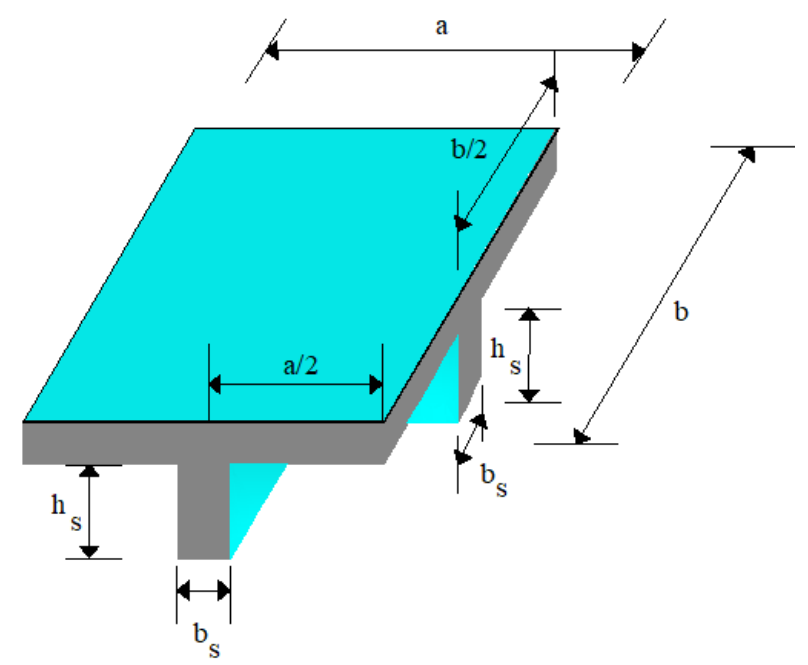

Fig. 9 The stiffened functionally graded plate with two stiffeners

Table 13 Nonlinear to linear frequency ratio $\omega_{N L} / \omega_{L}$ of (SSSS) square FGM stiffened plate with two stiffeners $\left(b_{s}=a / 30, h_{s}=5 h\right.$ and $\left.a / h=10\right)$

\begin{tabular}{|c|c|c|c|c|c|c|}
\hline \multirow[t]{2}{*}{$a / h$} & \multirow[t]{2}{*}{$n$} & \multicolumn{3}{|c|}{ (SSSS) } & \multicolumn{2}{|c|}{ central $/ h$} \\
\hline & & 0.2 & 0.4 & 0.6 & 0.8 & 1.0 \\
\hline \multirow[t]{6}{*}{10} & 0 & 1.0225 & 1.0476 & 1.0765 & 1.1083 & 1.1381 \\
\hline & 0.5 & 1.0219 & 1.0459 & 1.0735 & 1.1038 & 1.1362 \\
\hline & 1 & 1.0211 & 1.0450 & 1.0719 & 1.1013 & 1.1328 \\
\hline & 2 & 1.0205 & 1.0440 & 1.0702 & 1.0987 & 1.1291 \\
\hline & 5 & 1.0202 & 1.0432 & 1.0686 & 1.0963 & 1.1257 \\
\hline & 10 & 1.0201 & 1.0429 & 1.0681 & 1.0954 & 1.1245 \\
\hline
\end{tabular}


Table 14 Nonlinear to linear frequency ratio $\omega_{N L} / \omega_{L}$ of (SSSS) square FGM stiffened plate with two stiffeners $\left(b_{s}=a / 30, h_{s}=5 h\right.$ and $\left.a / h=20\right)$

\begin{tabular}{|c|c|c|c|c|c|c|}
\hline \multirow[t]{2}{*}{$a / h$} & \multirow[t]{2}{*}{$n$} & \multicolumn{3}{|c|}{ (SSSS) } & \multicolumn{2}{|c|}{ central $/ \mathrm{h}$} \\
\hline & & 0.2 & 0.4 & 0.6 & 0.8 & 1.0 \\
\hline \multirow[t]{6}{*}{20} & 0 & 1.0222 & 1.0468 & 1.0736 & 1.1022 & 1.1323 \\
\hline & 0.5 & 1.0217 & 1.0456 & 1.0713 & 1.0987 & 1.1276 \\
\hline & 1 & 1.0210 & 1.0447 & 1.0699 & 1.0966 & 1.1246 \\
\hline & 2 & 1.0201 & 1.0438 & 1.0683 & 1.0942 & 1.1214 \\
\hline & 5 & 1.0200 & 1.0429 & 1.0667 & 1.0918 & 1.1181 \\
\hline & 10 & 1.0199 & 1.0425 & 1.0660 & 1.0907 & 1.1166 \\
\hline
\end{tabular}

Table 15 Nonlinear to linear frequency ratio $\omega_{N L} / \omega_{L}$ of (CCCC) square FGM stiffened plate with two stiffeners $\left(b_{s}=a / 30, h_{s}=5 h\right.$ and $\left.a / h=10\right)$

\begin{tabular}{|c|c|c|c|c|c|c|}
\hline \multirow[t]{2}{*}{$a / h$} & \multirow[t]{2}{*}{$n$} & \multicolumn{3}{|c|}{ (CCCC) } & \multicolumn{2}{|c|}{$v_{\text {central }} / h$} \\
\hline & & 0.2 & 0.4 & 0.6 & 0.8 & 1.0 \\
\hline \multirow[t]{6}{*}{10} & 0 & 1.0024 & 1.0084 & 1.0180 & 1.0308 & 1.0467 \\
\hline & 0.5 & 1.0022 & 1.0079 & 1.0170 & 1.0292 & 1.0444 \\
\hline & 1 & 1.0021 & 1.0076 & 1.0164 & 1.0283 & 1.0430 \\
\hline & 2 & 1.0020 & 1.0073 & 1.0158 & 1.0273 & 1.0415 \\
\hline & 5 & 1.0019 & 1.0070 & 1.0152 & 1.0263 & 1.0401 \\
\hline & 10 & 1.0019 & 1.0069 & 1.0150 & 1.0259 & 1.0395 \\
\hline
\end{tabular}

Table 16 Nonlinear to linear frequency ratio $\omega_{N L} / \omega_{L}$ of (CCCC) square FGM stiffened plate with two stiffeners $\left(b_{s}=a / 30, h_{s}=5 h\right.$ and $\left.a / h=20\right)$

\begin{tabular}{ccccccc}
\hline$a / h$ & $n$ & \multicolumn{5}{c}{$w_{\text {central }} / h$} \\
\cline { 3 - 7 } & & 0.2 & 0.4 & 0.6 & 0.8 & 1.0 \\
\hline 20 & 0 & 1.0015 & 1.0047 & 1.0097 & 1.0164 & 1.0246 \\
& 0.5 & 1.0012 & 1.0040 & 1.0085 & 1.0145 & 1.0221 \\
& 1 & 1.0010 & 1.0036 & 1.0078 & 1.0135 & 1.0207 \\
& 2 & 1.0009 & 1.0033 & 1.0072 & 1.0125 & 1.0193 \\
& 5 & 1.0008 & 1.0030 & 1.0066 & 1.0116 & 1.0180 \\
& 10 & 1.0007 & 1.0028 & 1.0063 & 1.0112 & 1.0174 \\
\hline
\end{tabular}

Table 17 Nonlinear to linear frequency ratio $\omega_{N L} / \omega_{L}$ of (SSSS) square FGM stiffened plate with two stiffeners $\left(b_{s}=a / 50, h_{s}=5 h\right.$ and $\left.a / h=10\right)$

\begin{tabular}{|c|c|c|c|c|c|c|}
\hline \multirow[t]{2}{*}{$a / h$} & \multirow[t]{2}{*}{$n$} & \multicolumn{3}{|c|}{ (SSSS) } & \multicolumn{2}{|c|}{$w_{\text {central }} / \mathrm{h}$} \\
\hline & & 0.2 & 0.4 & 0.6 & 0.8 & 1.0 \\
\hline \multirow[t]{6}{*}{10} & 0 & 1.0224 & 1.0481 & 1.0793 & 1.1144 & 1.1527 \\
\hline & 0.5 & 1.0216 & 1.0462 & 1.0755 & 1.1087 & 1.1448 \\
\hline & 1 & 1.0212 & 1.0459 & 1.0736 & 1.1056 & 1.1405 \\
\hline & 2 & 1.0208 & 1.0448 & 1.0716 & 1.1025 & 1.1361 \\
\hline & 5 & 1.0205 & 1.0439 & 1.0698 & 1.0997 & 1.1320 \\
\hline & 10 & 1.0202 & 1.0436 & 1.0692 & 1.0988 & 1.1306 \\
\hline
\end{tabular}


Table 18 Nonlinear to linear frequency ratio $\omega_{N L} / \omega_{L}$ of (SSSS) square FGM stiffened plate with two stiffeners $\left(b_{s}=a / 50, h_{s}=5 h\right.$ and $\left.a / h=20\right)$

\begin{tabular}{|c|c|c|c|c|c|c|}
\hline \multirow[t]{2}{*}{$a / h$} & \multirow[t]{2}{*}{$n$} & \multicolumn{3}{|c|}{ (SSSS) } & \multicolumn{2}{|c|}{ central $/ h$} \\
\hline & & 0.2 & 0.4 & 0.6 & 0.8 & 1.0 \\
\hline \multirow[t]{6}{*}{20} & 0 & 1.0220 & 1.0475 & 1.0761 & 1.1074 & 1.1410 \\
\hline & 0.5 & 1.0214 & 1.0460 & 1.0734 & 1.1032 & 1.1350 \\
\hline & 1 & 1.0211 & 1.0451 & 1.0718 & 1.1007 & 1.1315 \\
\hline & 2 & 1.0207 & 1.0442 & 1.0701 & 1.0980 & 1.1278 \\
\hline & 5 & 1.0204 & 1.0433 & 1.0684 & 1.0955 & 1.1242 \\
\hline & 10 & 1.0200 & 1.0429 & 1.0678 & 1.0945 & 1.1227 \\
\hline
\end{tabular}

Table 19 Nonlinear to linear frequency ratio $\omega_{N L} / \omega_{L}$ of (CCCC) square FGM stiffened plate with two stiffeners $\left(b_{s}=a / 50, h_{s}=5 h\right.$ and $\left.a / h=10\right)$

\begin{tabular}{|c|c|c|c|c|c|c|}
\hline \multirow[t]{2}{*}{$a / h$} & \multirow[t]{2}{*}{$n$} & \multicolumn{3}{|c|}{ (CCCC) } & \multicolumn{2}{|c|}{$w_{\text {central }} / h$} \\
\hline & & 0.2 & 0.4 & 0.6 & 0.8 & 1.0 \\
\hline \multirow[t]{6}{*}{10} & 0 & 1.0026 & 1.0094 & 1.0201 & 1.0344 & 1.0521 \\
\hline & 0.5 & 1.0024 & 1.0087 & 1.0188 & 1.0323 & 1.0491 \\
\hline & 1 & 1.0023 & 1.0084 & 1.0181 & 1.0312 & 1.0473 \\
\hline & 2 & 1.0022 & 1.0080 & 1.0173 & 1.0299 & 1.0454 \\
\hline & 5 & 1.0021 & 1.0076 & 1.0166 & 1.0286 & 1.0436 \\
\hline & 10 & 1.0020 & 1.0075 & 1.0163 & 1.0282 & 1.0296 \\
\hline
\end{tabular}

Table 20 Nonlinear to linear frequency ratio $\omega_{N L} / \omega_{L}$ of (CCCC) square FGM stiffened plate with two stiffeners $\left(b_{s}=a / 50, h_{s}=5 h\right.$ and $\left.a / h=20\right)$

\begin{tabular}{ccccccc}
\hline$a / h$ & $n$ & \multicolumn{5}{c}{$w_{\text {central }} / h$} \\
\cline { 3 - 7 } & & 0.2 & 0.4 & 0.6 & 0.8 & 1.0 \\
\hline 20 & 0 & 1.0017 & 1.0055 & 1.0114 & 1.0193 & 1.0291 \\
& 0.5 & 1.0013 & 1.0046 & 1.0099 & 1.0170 & 1.0258 \\
& 1 & 1.0012 & 1.0042 & 1.0091 & 1.0158 & 1.0241 \\
& 2 & 1.0010 & 1.0039 & 1.0084 & 1.0147 & 1.0225 \\
& 5 & 1.0009 & 1.0035 & 1.0078 & 1.0136 & 1.0210 \\
& 10 & 1.0008 & 1.0033 & 1.0075 & 1.0131 & 1.0203 \\
\hline
\end{tabular}

The parameters to be changed are given as exactly the same as in the previous example. Once again, the numerical results based on this proposed method are given in Tables 1320. Furthermore, the first four mode shapes for a fully simply supported stiffened functionally graded plate with case $a / h=10, b_{s}=a / 30$ and $n=2$ are also depicted in Fig. 10. 


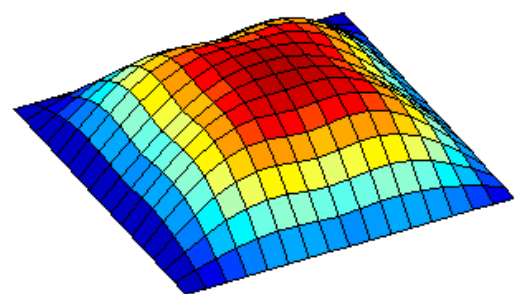

Mode 1

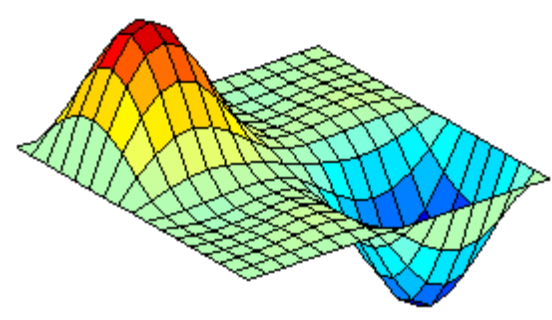

Mode 3

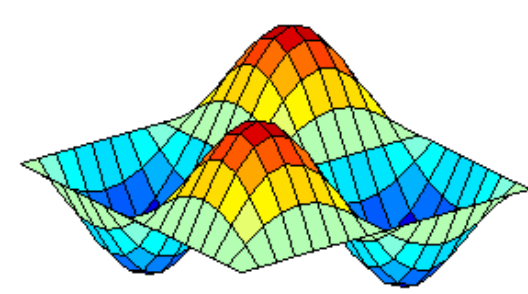

Mode 2

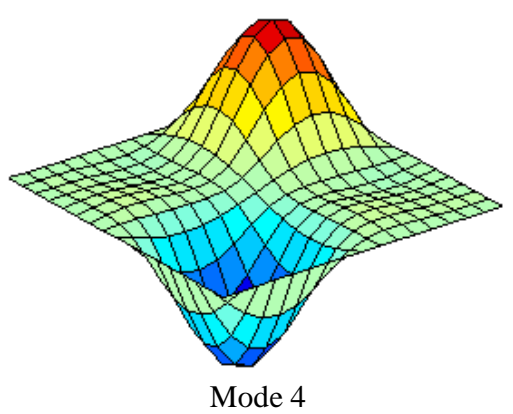

Fig. 10 The first four mode shapes of the functionally graded plate with two stiffeners

\section{CONCLUSIONS}

An efficient numerical method based on the new C0 third-order shear deformation theory with respect to the Shi theory is firstly developed for a nonlinear free vibration analysis of stiffened functionally graded plates. The Shi's third-order shear deformation theory with its necessary stability is then a revised form which only requires $\mathrm{C} 0$ continuity for displacement fields. In this $\mathrm{C} 0$ third-order shear deformation theory, two additional variables are joined, and thence the first derivative of transverse displacements is only required, respectively. Furthermore, the functionally graded materials with excellent characteristics of ceramic in corrosive resistances combined with the great toughness of metals in absorb energy and plastically deform, lead to outstanding advanced materials that can withstand extreme conditions of reality. This is even more wonderful if they are reinforced by stiffeners. From the above notions, this paper aims to provide mechanical information for this type of structure. In each case of the study with different data, the achieved results are found to agree well with the solutions of other numerical methods. Based on this proposed method, the present numerical solutions show a more stable procedure than others. And its applicability has been clearly shown in the section above. Finally, mechanical information from this paper might also be helpful to designers or researchers in appropriate selections of stiffened functionally graded plates for specific purposes. 


\section{REFERENCES}

1. Liew, K.M., Xiang, Y., Kitipornchai, S., Meek, J.L., 1995, Formulation of Mindlin-Engesser model for stiffened plate vibration, Computer Methods in Applied Mechanics and Engineering, 120(3), pp. 339-353.

2. Aksu, G., Ali, R., 1976, Free vibration analysis of stiffened plates using finite difference method, Journal of Sound and Vibration, 48(1), pp. 15-25

3. Zhou, X.Q., Yu, D.Y., Shao, X., Wang, S., Tian, Y.H., 2014, Band gap characteristics of periodically stiffened-thin-plate based on center-finite-difference-method, Thin-Walled Structures, 82, pp. 115-123.

4. Bhar, A., Phoenix, S.S., Satsangi, S.K., 2010, Finite element analysis of laminated composite stiffened plates using FSDT and HSDT: A comparative perspective, Composite Structures, 92(2), pp. 312-321.

5. Aishwary, S.R., Sharma, A.K., Gehlot, P., 2018, Free vibration analysis of Stiffened Laminated Plate using FEM, Materials Today: Proceedings, 5(2, Part 1), pp. 5313-5321.

6. Nguyen, M.N., Nguyen, T.T., Bui, X.T., Vo, D.T., 2015, Static and free vibration analyses of stiffened folded plates using a cell-based smoothed discrete shear gap method (CS-FEM-DSG3), Applied Mathematics and Computation, 266, pp. 212-234.

7. Bui, T.Q., Do, T.V., Ton, T.H.L, Doan, D.H., Tanaka, S., Pham, D.T., Nguyen, V.T.A., Yu, T., Hirose, S., 2016, On the high temperature mechanical behaviors analysis of heated functionally graded plates using FEM and a new third-order shear deformation plate theory, Composites Part B: Engineering, 92, pp. 218-241.

8. Ton, T.H.L., Nguyen, V.H., Chau, D.T., 2020, An improved four-node element for analysis of composite plate/shell structures based on twice interpolation strategy, International Journal of Computational Methods, 17(6), 1950020.

9. Ton, T.H.L., Nguyen, V.H., Chau, D.T., 2020, Nonlinear bending analysis of functionally graded plates using SQ4T elements based on twice interpolation strategy, Journal of Applied and Computational Mechanics, 6(1), pp. 125-136.

10. Ton, T.H.L., Nguyen, V.H., Chau, D.T., Huynh, V.C., 2018, Enhancement to four-node quadrilateral plate elements by using cell-based smoothed strains and higher-order shear deformation theory for nonlinear analysis of composite structures, Journal of Sandwich Structures \& Materials, 22, pp. 2302-2329.

11. Nguyen, V.H., Ton, T.H.L., Chau, D.T., Dao, N.D., 2018, Nonlinear static bending analysis of functionally graded plates using MISQ24 elements with drilling rotations, Proc. International Conference on Advances in Computational Mechanics 2017, Springer Singapore, 15479070.

12. Ton, T.H.L., 2020, Finite element analysis of functionally graded skew plates in thermal environment based on the new third-order shear deformation theory, Journal of Applied and Computational Mechanics, 6(4), pp. 1044-1057.

13. Ton, T.H.L., 2020, Improvement on eight-node quadrilateral element (IQ8) using twice-interpolation strategy for linear elastic fracture mechanics, Engineering Solid Mechanics, 8(4), pp. 323-336.

14. Rama, G., Marinkovic, D., Zehn, M., 2018, High performance 3-node shell element for linear and geometrically nonlinear analysis of composite laminates, Composites Part B: Engineering, 151, pp. 118-126.

15. Marinković, D., Gil, R., Zehn, M., 2019, Abaqus implementation of a corotational piezoelectric 3-node shell element with drilling degree of freedom, Facta Universitatis-Series Mechanical Engineering, 17(2), pp. 269-283.

16. Kamineni, J.N., Burela, R.G., 2019, Constraint method for laminated composite flat stiffened panel analysis using variational asymptotic method (VAM), Thin-Walled Structures, 145, 106374.

17. Rossow, M.P., Ibrahimkhail, A.K., 1978, Constraint method analysis of stiffened plates, Computers \& Structures, 8(1), pp. 51-60.

18. Peng, L.X., Liew, K.M., Kitipornchai, S., 2007, Analysis of stiffened corrugated plates based on the FSDT via the mesh-free method, International Journal of Mechanical Sciences, 49(3), pp. 364-378.

19. Peng, L.X., Liew, K.M., Kitipornchai, S., 2006, Buckling and free vibration analyses of stiffened plates using the FSDT mesh-free method, Journal of Sound and Vibration, 289(3), pp. 421-449.

20. Liew, K.M., Kitipornchai, S., Peng, L.X., 2006, 4 - Mesh-free methods for buckling analysis of stiffened and corrugated plates, in Analysis and Design of Plated Structures, N.E. Shanmugam and C.M. Wang, Editors. 2006, Woodhead Publishing, pp. 80-116.

21. Mukhopadhyay, M., 1989, Vibration and stability analysis of stiffened plates by semi-analytic finite difference method, Part I: Consideration of bending displacements only, Journal of Sound and Vibration, 130(1), pp. 27-39.

22. Mukhopadhyay, M., 1989, Vibration and stability analysis of stiffened plates by semi-analytic finite difference method, part II: Consideration of bending and axial displacements, Journal of Sound and Vibration, 130(1), pp. 41-53. 
23. Zahari, R., El-Zafrany, A., 2009, Progressive failure analysis of composite laminated stiffened plates using the finite strip method, Composite Structures, 87(1), pp. 63-70.

24. Sheikh, A.H., Mukhopadhyay, M., 2000, Geometric nonlinear analysis of stiffened plates by the spline finite strip method, Computers \& Structures, 76(6), pp. 765-785.

25. Sheikh, A.H., Mukhopadhyay, M., 1992, Analysis of stiffened plate with arbitrary planform by the general spline finite strip method, Computers \& Structures, 42(1), pp. 53-67.

26. Leme, S.P.L., Aliabadi, M.H., 2012, Dual boundary element method for dynamic analysis of stiffened plates, Theoretical and Applied Fracture Mechanics, 57(1), pp. 55-58.

27. Tanaka, M., Bercin, A.N., 1998, Static bending analysis of stiffened plates using the boundary element method, Engineering Analysis with Boundary Elements, 21(2), pp. 147-154.

28. Varghese, V., 2018, An analysis of thermal-bending stresses in a simply supported thin elliptical plate, Journal of Applied and Computational Mechanics, 4(4), pp. 299-309.

29. Sayyad, A., Ghumare, S., 2019, A new quasi-3D model for functionally graded plates, Journal of Applied and Computational Mechanics, 5(2), pp. 367-380.

30. Zargaripoor, A., Daneshmehr, A.R., Nikkhah Bahrami, M., 2019, Study on free vibration and wave power reflection in functionally graded rectangular plates using wave propagation approach, Journal of Applied and Computational Mechanics, 5(1), pp. 77-90.

31. Vel, S.S., Batra, R.C., 2002, Exact solution for thermoelastic deformations of functionally graded thick rectangular plates, AIAA Journal, 40(7), pp. 1421-1433.

32. Sedighi, H.M., Malikan, M., 2020, Stress-driven nonlocal elasticity for nonlinear vibration characteristics of carbon/boron-nitride hetero-nanotube subject to magneto-thermal environment, Physica Scripta, 95(5), 055218.

33. Ouakad, H.M., Valipour, A., Kamil Żur, K., Sedighi, H.M., Reddy, J.N., 2020, On the nonlinear vibration and static deflection problems of actuated hybrid nanotubes based on the stress-driven nonlocal integral elasticity, Mechanics of Materials, 148, 103532.

34. Qian, L.F., Batra, R.C., Chen, L.M., 2003, Free and forced vibrations of thick rectangular plates using higher-order shear and normal deformable plate theory and meshless Petrov-Galerkin (MLPG) method, Computer Modeling in Engineering \& Sciences, 4(5), pp. 519--534.

35. Rama, G., Marinković, D., Zehn, M., 2017, Efficient three-node finite shell element for linear and geometrically nonlinear analyses of piezoelectric laminated structures, Journal of Intelligent Material Systems and Structures, 29(3), pp. 345-357.

36. Shi, G., 2007, A new simple third-order shear deformation theory of plates, International Journal of Solids and Structures, 44(13), pp. 4399-4417.

37. Mukherjee, A., Mukhopadhyay, M., 1988, Finite element free vibration of eccentrically stiffened plates, Computers \& Structures, 30(6), pp. 1303-1317.

38. Harik, I.E., Guo, M., 1993, Finite element analysis of eccentrically stiffened plates in free vibration, Computers \& Structures, 49(6), pp. 1007-1015.

39. Dayi, O., Mak., C.M., 2012, Free flexural vibration analysis of stiffened plates with general elastic boundary supports, World Journal of Modelling and Simulation, 8(2), pp. 96-102.

40. Shen, H.S., 2009, Functionally Graded Materials Nonlinear Analysis of Plates and Shells, New York, NY, USA: CRC Press Taylor \& Francis Group. 